1. Department of Pharmacology, Ziauddin University, Karachi, Pakistan

2. Assistant Professor,

King Saud bin Abdulaziz University for Health Sciences (KSAU-HS)-WR

3. Professor, Department of

Pharmaceutics,

Ziauddin University, Karachi,

Pakistan

4. Chairman Department of Medicine Aga Khan Hospital, Dar es salaam, Tanzania

5. Department of Pharmacology, Ziauddin University, Karachi, Pakistan

6. Quality control officer,

Mektum Industry. Pvt. Ltd

Correspondence Address:

Noor ul Ain

Department of Pharmacology,

Ziauddin University, Karachi, Pakistan

Faculty of Pharmacy, Ziauddin

University,

ST-4B, Shahrah-e-Ghalib, Block-6,

Clifton, Karachi, Pakistan.

siddiquinoorulain@gmail.com

Article received on:

08/09/2016

Accepted for publication:

30/12/2016

Received after proof reading:

14/02/2017

\section{HEMATOLOGICAL TOXICITY IN RATS; THERAPEUTIC PROPERTIES OF ANDROGRAPHIS PANICULATA ON OXALIPLATIN INDUCED}

\begin{abstract}
Noor ul Ain', Nusrat Bano², Anwar Ejaz Beg ${ }^{3}$, Kamran Hameed ${ }^{4}$, Talha Bin Fayyaz ${ }^{5}$, Rafia Sadaf ${ }^{6}$
ABSTRACT... Objectives: Oxaliplatin causes hematological toxicities in clinical setting which limits its efficacy. The aim of this study is to investigate the therapeutic effects of Andrographis paniculata against hematological toxicity caused by oxaliplatin. Study design: Experimental animal study. Period: Study takes 8 month from March 2015 to Oct 2015. Setting: Dow university animal house. Method: Wistar albino male rats, divided into 3 equals groups $(n=6)$ : Group $\mathrm{N}^{*}$ was a control group $(0.9 \%$ normal saline), Group NPO was Oxaliplatin treated group and Group NP1 was prophylactically treated with Andrographis paniculata followed by Oxaliplatin in order to assess the protective effects of Andrographis paniculata against the hematologic toxicity caused by Oxaliplatin. Results: Prophylactic treatment with Andrographis paniculata (NP1) significantly increases the levels of platelets and neutrophile count compared with the standard (NPO) $(p<0.01)$ and increases the RBCs count and levels of hemoglobin compared with the standard (NPO). Conclusion: Prophylactic treatment with Andrographis paniculata (NP1) was effective in reducing risk of thrombocytopenia, anemia and neutropenia associated with Oxaliplatin.
\end{abstract}

Key words: $\quad$ Andrographis Paniculata, Hematotoxicity, Oxaliplatin, Rats.

Article Citation: Ain N, Bano N, Beg AE, Hameed K, Fayyaz TB, Sadaf R. Hematological toxicity in rats; therapeutic properties of andrographis paniculata on oxaliplatin induced. Professional Med J 2017;24(2):342-346.

DOI: $10.17957 / T P M J / 17.3720$
INTRODUCTION

Andrographis paniculata (family Acanthaceae) is a native of tropical and subtropical lands. Andrographis paniculata identified as Hempedu Bumi and generally known as King of Bitter extensively cultivate in the tropical area of India, China and South East Asia. ${ }^{1}$ Leaves contain an active phytoconstituent which is Andrographolide ${ }^{2}$ and has anti-inflammatory ${ }^{3}$ and hepatoprotective properties. ${ }^{4}$ Andrographis paniculata extract improves activity of antioxidant enzymes i.e. glutathione-Stransferase, superoxide dismutase and catalase. ${ }^{5}$ It also considerably reduces lipid peroxidation but significantly enhance concentrations of hepatic glutathione. ${ }^{6}$ By inhibiting cell cycle progression, Andrographolide produces anticancer effects against human colorectal carcinoma LoVo cells. ${ }^{7}$ Andrographis paniculata produces protective effects against carbon tetra chloride $\left(\mathrm{CCl}_{4}\right)$ caused lipid peroxidation and liver damage. ${ }^{8}$ Andrographolide inhibits nitric oxide (NO). ${ }^{9}$ and oxygen radical production in neutrophils ${ }^{3}$, inhibits NF-kB (controls DNA transcription and production of cytokine) activity $^{10}$, TNF-a and IL-12 production ${ }^{11}$ and migration of macrophage. ${ }^{12}$ The aqueous extract of Andrographis paniculata reduced oxidative stress in lymphocytes isolated from rat when exposed to nicotine. ${ }^{13}$ Andrographolide and 14-deoxy-11,12didehydroandrographolide drastically inhibited thrombin-induced aggragation of platelet while neoandrographolide has little or no activity. ${ }^{14}$

Oxaliplatin is a agent that blocks DNA replication by forming platinum-DNA adducts which leads to cell cycle arrest and cell death. ${ }^{15}$ Thrombocytopenia and neutropenia was a frequent toxicity seen during oxaliplatin treatment. ${ }^{16,17}$ Oxaliplatin produces cytotoxic effects by initiating production of reactive oxygen species and make intra- and interstrand cross-links with DNA, DNA-protein adducts and thereby inducing DNA damage and apoptosis. ${ }^{18,19}$ 
The purpose of this study is to reduce the hematotoxic effects of Oxaliplatin and enhances the clinical efficacy of oxaliplatin by using the herbal drug (Andrographis paniculata) which possesses hematoprotective effects.

\section{MATERIAL \& METHOD}

The experimental study was designed in the Department of Pharmacology, Ziauddin University and conducted in DUHS (Dow University of Health Sciences), succeeding institutional and ethical approval. Three treatment groups $(n=6)$, i.e. each consisting of 6 animals in each group, were designed; $\mathrm{N}^{*}$ (control) was the group to which we administered normal saline $0.9 \%$, NP0 (standard) received oxaliplatin and NP1 was the group received prophylactic treatment with Andrographis paniculata followed by oxaliplatin. Second phase of our study was to assess the changes in hematological profile for which complete blood count was conducted of each animal in a group.

Male albino Wistar rats 220 to $310 \mathrm{~g}$ were purchased from Dow University animal house. Animals were housed in properly ventilated, spacious animal house of Dow University of health sciences. Relative humidity (65-75\%) and temperature $23 \pm 2^{\circ} \mathrm{C}$ was maintained with alternating $12 \mathrm{hr}$ light and $12 \mathrm{hr}$ dark cycles. Animal Food and tap water was provided adlibitum.

Five hundred grams of leaves of Andrographis paniculata were collected, washed and air dried. Leaves were grinded using standard grinding machine. Powder drug was macerated in analytical grade ethanol for 48 hours. Powdered leaves $(10 \mathrm{gm})$ were extracted out successively with $100 \mathrm{ml}$ of ethanol. Extraction was carried out in standard soxhlet apparatus at $40-50^{\circ} \mathrm{C}$. The extract concentrate was stored in a refrigerator at $4^{\circ} \mathrm{C}$. Extract concentrate of Andrographis paniculata was prepared in 5\% DMSO solution (dimethyl sulfoxide) with water for injection for administration by oral route.

The albino wistar rats males were randomized to experimental and control groups, and divided into 3groups comprises of 6 animals in each group.

\section{Control N*}

Animals in group $\mathrm{N}^{*}$ served as the control group, where $2 \mathrm{ml}$ of $0.9 \%$ normal saline was administered i.p for 6 weeks.

\section{Standard NPO}

Animals grouped in NPO received Oxaliplatin 0.8 $\mathrm{mg} / \mathrm{kg}$ body mass intraperitoneally ${ }^{20}$ for one week (day 1 and 6).

\section{Group NP1}

Animals in Group NP1 were administered Andrographis paniculata prophylactically by oral route $(400 \mathrm{mg} / \mathrm{kg}$ body mass/day for 5 weeks) followed by Oxaliplatin $0.8 \mathrm{mg} / \mathrm{kg}$ i.p.for one week (day 1 and 6).

Albino wistar rats were housed for 56 days in animal house. Control time before and after dosing was 7 days with sufficient rat chow. Scheduled sacrifice/cardiac puncture was carried out on $7^{\text {th }}$ day after last dose i.e. on day 56 .

Blood drawn by cardiac puncture was collected in anticoagulant tubes. For estimation of hematological parameters, blood $(2 \mathrm{ml})$ was collected in EDTA K3 tubes for examination of Red Blood Cells, Hemoglobin, Leucocytes, Platelets, Neutrophils, Lymphocytes, Eosinophils, Monocytes on automatic Humacount plus Hematology analyzer Model \# 16400/S, (Human Germany).

\section{STATISTICAL ANALYSIS}

Data was analyzed on SPSS version 19 with paired sample test, $p$ value $<0.05$ was considered significant, $p$ value $<0.01$ highly significant and $p$ value $<0.001$ was considered very highly significant.

\section{RESULTS}

Figure-3\&4and Table-I.shows that the hemoglobin $(\mathrm{Hb})$ levels highly significant increased $(p<0.01)$ and the levels of RBCs significantly increased $(p<0.05)$ in the group treated with Andrographis paniculata compared with standard (NP0). 
Figure-1 and Table-I shows that Leucocyte count was very highly significantly decreased $(p<0.001)$ in the group NP1. Figure-2 and Table-I shows that Platelet count and neutrophil count was highly significantly increased $(p<0.01)$ in group NP1. Figure-1 and Table-I reveal that lymphocyte count was insignificantly affected $(p>0.05)$ in group NP2. Table-I shows that eosinophil count was significantly increased $(p<0.05)$ in group NP1 and the monocyte count was significantly decreased $(p<0.05)$ in group NP1.

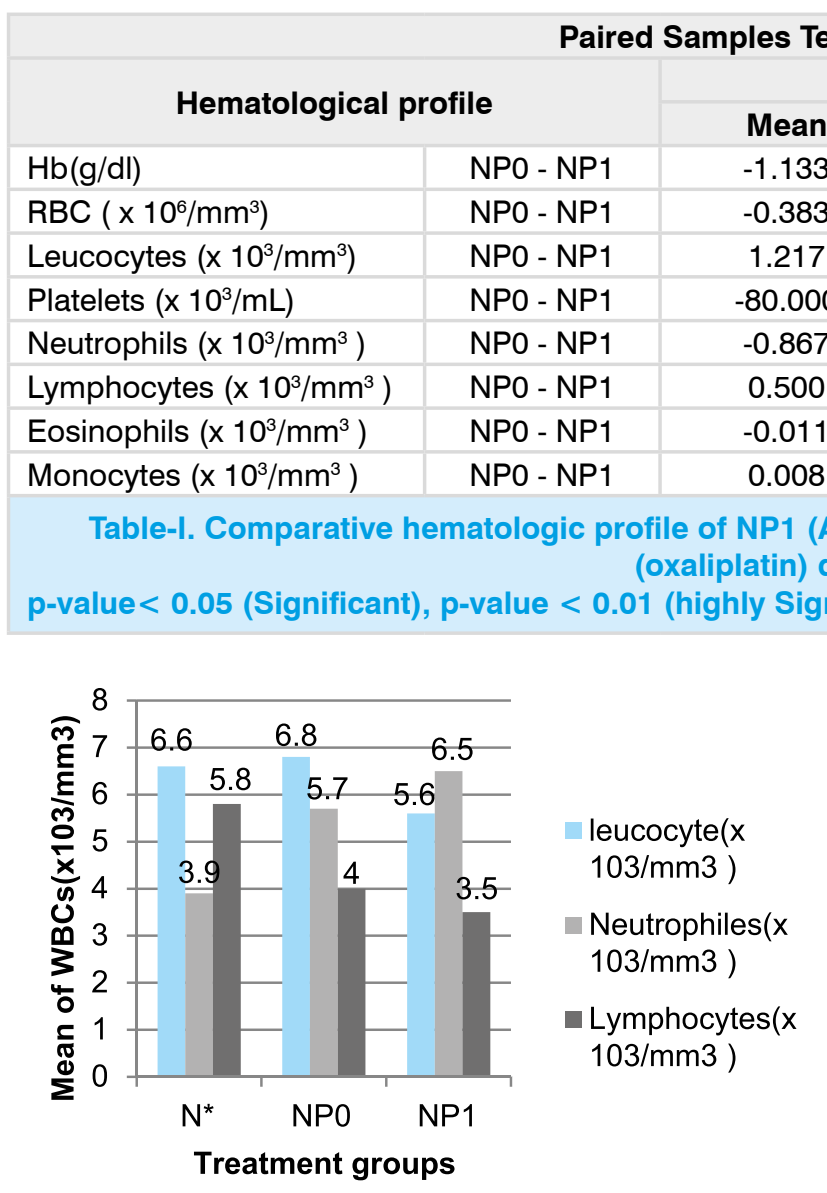

Figure-1. Comparative difference in the levels of WBCs

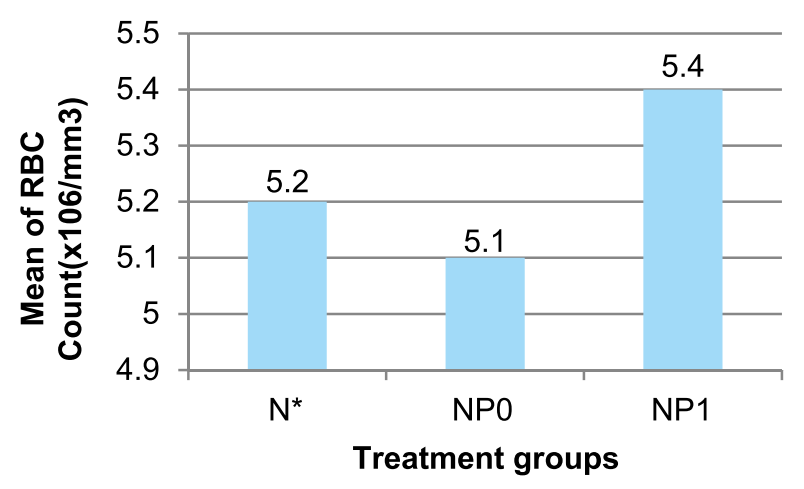

Figure-3. Comparative difference in the levels of RBCs

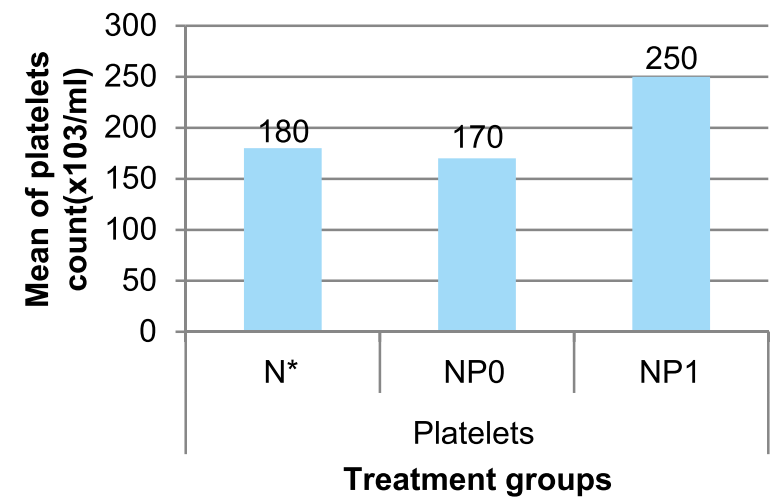

Figure-2. Comparative difference in the levels of Platelets.

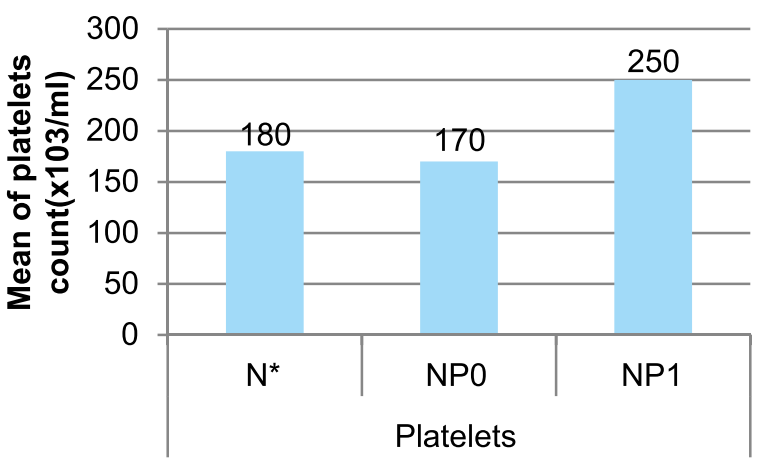

Treatment groups

Figure-4. Comparative difference in the levels of hemoglobin. 


\section{DISCUSSION}

Prophylactic treatment with Andrographis paniculata increases the platelet count compared with the standard (NP0). Thrombocytopenia was a frequent toxicity seen during oxaliplatin therapy. It occurs at any grade up to $70 \%$ of patients and leading to delays or even discontinuation of the chemotherapy. ${ }^{16}$ The present study indicates that the prophylactic treatment with the Andrographis paniculata overcome the reduce levels of platelets induced by oxaliplatin i.e. reduced the occurrence of thrombocytopenia induced by Oxaliplatin. Prophylactic treatment with Andrographis paniculata increases neutrophil count compared with the standard (NP0). There was higher incidence of grade 3 or 4 neutropenia associated with oxaliplatin therapy. ${ }^{17}$ This reveals that the prophylactic treatment with this agent decreases the incidence of neutropenia associated with Oxaliplatin and increases the efficacy of oxaliplatin. Lymphocyte count was insignificantly decreased in the group prophylactically treated with Andrographis paniculata (NP1). Andrographolide inhibits nitric oxide (NO) and oxygen radical production in neutrophils and inhibits macrophage migration as discussed above; indicate anti-inflammatory effects of Androgaphis paniculata. Serious anemic condition was not frequently associated with Oxaliplatin except Evans' syndrome and immune hemolytic anemia which was rarely reported adverse events with oxaliplatin. ${ }^{21}$ Prophylactic treatment with extract of Andrographis paniculata was effective in reducing the anemia associated with chemotherapy as it increase the levels of RBCs and $\mathrm{Hb}$ compared with standard (NP0) and further investigation is required to check the potential drug effect in reducing the immune induced thrombocytopenia and anemia .

Ethanolic extract of Andographis paniculata also produces cytoxicity and was effective against hepatic, lymphatic and colon human cancer cells. ${ }^{22}$ It is suggested that prophylactic treatment with Andrographis paniculata followed by oxaliplatin administration will be effective as it may decrease the side effects caused by oxaliplatin plus enhance the antiproliferative activity of oxaliplatin.
Andrographolide stimulates the production of cytotoxic T lymphocytes and hence inhibit tumor growth in animals. ${ }^{23}$ Prophylactic treatment with Ethanolic extract of Andrographis paniculata insignificantly decreases the levels of lymphocyte compared to the group treated with oxaliplatin alone. This indicates that the extract modulates the immune system but further investigation is required to figure out the beneficial effects of this drug against the hematic toxicity induced by oxaliplatin.

\section{CONCLUSION}

Prophylactic treatment with Andrographis paniculata was effective in reducing the risk of thromobocytopenia and neutropenia induced by oxaliplatin. Prophylactic treatment with Andrographis paniculata increases the levels of $\mathrm{RBC}$ and hemoglobin compared with standard (NP0) i.e. the drug have the potential to decrease the occurrence of anemia caused by Oxaliplatin.

Copyright( 30 Dec, 2016.

\section{REFERENCES}

1. Calabrese C, Berman SH, Babish JG, Ma X, Shinto L, Dorr M. A phase I trial of andrographolide in HIV positivepatients and normal volunteers. Phytother Res 2000, 14(5):333-338.

2. Du $Q$, Jerz $G$, and Winterhalter $P$. Separation of andrographolide and neoandrographolide from the leaves of Andrographis paniculata using highspeed counter-current chromatography. Journal of Chromatography A 2003; 984(1): 147-151.

3. Shen YC, Chen CF, Chiou WF. Andrographolide prevents oxygen radical production by human neutrophils: possible mechanism(s) involved in its anti-inflammatory effect. $\mathrm{Br} \mathrm{J}$ Pharmacol. 2002; 135(2): 399-406.

4. Trivedi NP and Rawal UM. Hepatoprotective and antioxidant property of Andrographispaniculata (Nees) in BHC induced liver damage in mice. Indian Journal of Experimental Biology.2001; 39(1): 41-46.

5. Verma $\mathrm{N}$, Vinayak $\mathrm{M}$.Antioxidant action of Andrographispaniculata on lymphoma. Mol. Biol. Rep. 2008; 35: 535-540.

6. Zhang XF and Tan BKH. Anti-diabetic property of ethanolic extract of Andrographispaniculata in streptozotocindiabeticrats. ActaPharmacologicaSinica 2000; 21(12): 1157-1164. 
7. Shi MD, Lin HH, Lee YC, Chao JK, Lin RA, and Chen $\mathrm{JH}$. Inhibition of cell-cycle progression in human colorectal carcinoma Lovo cells by andrographolide. Chemico-Biological Interactions. 2008; 174(3): 201210.

8. Jayakumar T, Hsieh CY, Lee JJ and RongSheu J. Review Article Experimental and Clinical Pharmacology of Andrographis paniculata and Its Major Bioactive Phytoconstituent Andrographolide. Evidence-Based Complementary and Alternative Medicine. 2013; Volume 2013: 16 pages. Article ID 846740,

9. Chiou WF, Chen CF, Lin JJ. Mechanisms of suppression of inducible nitric oxide synthase (iNOS) expression in Raw264.7 cells by andrographolide. Br J Pharmacol 2000, 129: 1553-1560.

10. Hidalgo MA, Romero A, Figueroa J, Cortes P, Concha II, Hancke JL, et al. Andrographolide interferes with binding of nuclear factor-KB to DNA in HL-60-derived neutrophilic cells. Br J Pharmacol 2005; 144: 680-686.

11. Qin LH, Kong L, Shi GJ, Wang ZT, Ge BX. Andrographolide inhibits the production of TNF-a and IL-12 in LPS stimulated macrophages: role of mitogen activated protein kinases. Biol Pharm Bull 2006; 29: 220-224.

12. Tsai HR, Yang LM, Tsai WJ, Chiou WF. Andrographolide acts through inhibition of ERK $1 / 2$ and Akt phosphorylation to suppress chemotactic migration. Eur J Pharmacol 2004, 498(1-3): 45-52.

13. Das S, Neogy S, Gautam N, Roy S. In vitro nitotine induced superoxide mediated DNA fragmentation in lymphocytes: protective role of Andrographis paniculata Nees. Toxicol in Vitro 2009; 23: 90-98.

14. Chao WW and Lin BF. Isolation and identification of bioactive compounds in Andrographispaniculata (Chuanxinlian).Chao and Lin Chinese Medicine 2010; 5: 17.
15. Kelland $L$. The resurgence of platinum-based cancer chemotherapy. Nat Rev Cancer 2007; 7: 573-584.

16. Jardim DL, Rodrigues CA, Novis YAS, Rocha VG \& Hoff PM. Review Oxaliplatin-related thrombocytopenia. Annals of Oncology 2012; 23(8): 1937-1942.

17. Haller DG. Safety of oxaliplatin in the treatment of colorectal cancer. Oncology (Williston Park) 2000; 12(11): 15-20.

18. Wang D, Lippard SJ. Cellular processing of platinum anticancer drugs. Nat Rev Drug Discov. 2005; 4(4): 307-320.

19. Brozovic A, Ambriovic-Ristov A, Osmak M. The relationship between cisplatin-induced reactive oxygen species, glutathione, and BCL-2 and resistance to cisplatin. Crit Rev Toxicol. 2010; 40(4): 347-359.

20. Najam R, Bano N, Mirza T and Hassan S. Adverse effects on cardiovascular status and lipid levels of albino Wistar rats treated with cisplatin and oxaliplatin in combination with 5 Fluorouracil. Pak. J. Pharm. Sci.2014; 27(5): 1409-1418.

21. Koutras AK, Makatsoris T, Paliogianni F, Kopsida G, Onyenadum A, Gogos CA, et al. Oxaliplatin-Induced Acute-Onset Thrombocytopenia, Hemorrhage and Hemolysis .A Case Report and Review of the Literature. Oncology 2004; 67: 179-182.

22. Geethangili $\mathrm{M}$, Rao $\mathrm{YK}$, Fang $\mathrm{SH}$, and Tzeng $\mathrm{YM}$. Cytotoxic constituents from Andrographis paniculata induce cell cycle arrest in Jurkat cells. Phytotherapy Research. 2008; 22(10):1336-1341.

23. Sheeja K and Kuttan G. Activation of cytotoxic $\mathbf{T}$ lymphocyte responses and attenuation of tumor growth in vivo by Andrographis paniculata extract and andrographolide. Immunopharmacology and Immunotoxicology. 2007; 29(1): 81-93.

\section{AUTHORSHIP AND CONTRIBUTION DECLARATION}

\begin{tabular}{|c|c|c|c|}
\hline Sr. \# & Author-s Full Name & Contribution to the paper & Author $=\mathbf{s}$ Signature \\
\hline 1 & Noor ul Ain & $\begin{array}{l}\text { Concept, analysis, writeup and drafting. } \\
\text { Perform expertimental work and extraction }\end{array}$ & \\
\hline 2 & Nusrat Bano & of herbs. & \\
\hline 3 & Anwar Ejaz Beg & $\begin{array}{l}\text { approval of manuscript. } \\
\text { Give his expert view for manuscript }\end{array}$ & \\
\hline 4 & Kamran Hameed & Gesigning and finallzıng the manuscript & \\
\hline 5 & Talha Bin Fayyaz & $\begin{array}{l}\text { Help in experimental work, Data collection } \\
\text { and manuscript writing. }\end{array}$ & \\
\hline 6 & Rafia Sadaf & Help in data collection. & \\
\hline
\end{tabular}

